\title{
OS SENTIDOS DA PALAVRA FAMÍLIA A PARTIR DE ABORDAGENS ACERCA DE UNIÃO ESTÁVEL
}

\author{
Byron de Castro Muniz Teixeira* \\ Adilson Ventura ${ }^{* *}$
}

RESUMO: Este artigo tem como objetivo analisar o sentido da palavra família em enunciados do livro Direito de Família, de Pablo Stolze Gagliano e Rodolfo Pamplona Filho, entendido como um livro doutrinário que visa fazer o estudioso do Direito interpretar a Lei e entender seu funcionamento na sociedade. Selecionamos, como corpus para análise, três recortes que indicam o entendimento da Doutrina acerca da União Estável e a possível interpretação dos Juristas. Nossa análise se dará no campo teórico da Semântica do Acontecimento, observando como se dá as relações no espaço da enunciação, que é um espaço político, constituído pelos locutores e pela língua. A Semântica do Acontecimento conceitua a enunciação como uma prática política, que instala o conflito no centro do dizer, e para quem a constituição dos sentidos é histórica e a relação do sujeito com a língua ocorre no acontecimento. Como suporte metodológico, serão observados os sentidos e as relações dos termos em textos extraídos do livro Direito de Família, a partir das relações nas enunciações. Para tanto, utilizaremos os procedimentos de reescrituração, articulação e Domínio Semântico de Determinação (D.S.D.). Ademais utilizaremos paráfrases que servirão de sustentação para as possíveis conclusões. Percebe-se que os enunciados analisados apontam para lugares em que se percebe um embate de sentidos, que coloca de um lado a lei, a qual impõe um casamento formal, com caráter heterossexual, enquanto a união estável, também denominada no recorte, como união de fato, é constituída "à margem" da lei, sendo desprovida de solenidades e inferior ao casamento.

PALAVRAS-CHAVE: Direito; Semântica; Sentidos; União estável.

\section{Introdução}

Neste trabalho', apresentamos como recortes as discussões do livro intitulado Novo Curso de Direito Civil - Direito de Família, Volume 6, da autoria de Pablo Stolze Gagliano e Rodolfo Pamplona Filho (2020), de onde extrairemos alguns recortes para produzirmos algumas análises a respeito dos sentidos da palavra família, advindas de espaços da enunciação,

\footnotetext{
* Doutorando em Linguística pela Universidade Estadual do Sudoeste da Bahia (Uesb). Mestre em Memória: Linguagem e Sociedade pela Uesb. Professor da Universidade Estadual do Sudoeste da Bahia (Uesb).

** Doutor em Linguística pela Universidade Estadual de Campinas (Unicamp). Professor Titular da Universidade Estadual do Sudoeste da Bahia (Uesb).

${ }^{1}$ Este trabalho é uma versão de uma comunicação oral feita à XXVIII Jornada do Grupo de Estudos Linguísticos e Literários do Nordeste (GELNE), realizada entre 03 a 13 de novembro de 2020.
} 
que constroem e reconstroem concepções, possibilitando novos sentidos de família. Para tanto, utilizaremos como fundamento teórico de análise, a Semântica do Acontecimento, de cunho materialista-histórico e analisaremos as discussões sobre os modos de acesso à palavra e as categorias de análise como reescrituração, articulação, paráfrases e Domínio Semântico de Determinação (DSD).

Este trabalho coloca em questão o sentido do termo família, significada a partir de enunciados contidos no Direito, especialmente na Doutrina. Podemos entender a Doutrina como um conjunto de ideias, opiniões, conceitos que servem de sustentação para teorias e interpretações da ciência jurídica. É nesse espaço da enunciação que buscamos analisar construções de sentidos do termo família, tendo em vista os sentidos apresentados nos enunciados acerca do termo.

Assim, nosso objetivo é analisar os sentidos desta palavra no espaço jurídico, a partir da leitura do livro Direito de Família, da autoria de Pablo Stolze Gagliano e Rodolfo Pamplona Filho (2020), considerando o jurídico e o político-social na sua constituição, tomando como lugar de observação o espaço enunciativo brasileiro e mais especificamente nessa referida obra, referência do pensamento jurídico, a construção dos sentidos da palavra família.

Para tanto, utilizaremos os fundamentos da Semântica do Acontecimento, que considera que a construção dos sentidos se dá numa relação da língua com a própria língua, levando em consideração que essa relação é tomada na história. Assim, consideramos o espaço de enunciação, um espaço político, no qual os sentidos se cruzam, se dividem, redividem, se transformam. Pela Semântica do Acontecimento, considera-se, a partir da linguagem, a relação da mesma com os sujeitos, o real, a historicidade, o social e o político na constituição dos sentidos.

Para entendermos a construção dos sentidos de família, analisamos as cenas enunciativas, nas quais se integram estas expressões, que estabeleceram o sentido de família no texto a partir de recortes apresentados e ocorridos nesse espaço de enunciação, que constroem e desconstroem entendimentos a respeito de família. Assim, para esse nosso trabalho, iremos primeiro apresentar um breve histórico sobre a família, depois alguns aspectos teóricos, apresentaremos nossas análises e, por fim, as conclusões a que este trabalho nos permitiu chegar.

\section{Breve histórico de família}

A familia surge com os primeiros agrupamentos humanos, assim considerados núcleos familiares, na medida em que a união de pessoas com a finalidade de proteção recíproca, 
produção e/ou procriação, já se permitia o desenvolvimento do afeto e da procura da completude existencial. (GAGLIANO; PAMPLONA, 2020, p. 45).

Entretanto, apesar da existência de família nesses primeiros agrupamentos humanos, a palavra família surge no Direito Romano, oriunda do vocábulo famulus, que designava o conjunto de escravos pertencentes a um determinado grupo e este grupo era comandado por uma figura geralmente do sexo masculino, o paterfamílias. Este era um ascendente mais velho de um determinado núcleo, que reunia os descendentes sob a mais absoluta autoridade, formando assim, o que se passou a denominar família (LOBO, 2009, p. 8). Assim, a origem do vocábulo nasce das relações entre escravos pertencentes a um grupo ou grupos e a este conjunto de escravos deu-se o nome de famulus, pois pertencia àquele grupo.

Ademais, ainda no Império Romano, a família e a propriedade eram sinônimas, tanto que uma unidade patrimonial só era reconhecida quando tinha como titular um pater familias e este era "dono" de tudo e de todos. Desta forma, quando este falecia, desmembra-se a família, tornando-se cada um dos seus descendentes masculinos um novo pater de suas respectivas familias (GAGLIANO; PAMPLONA, 2020, p. 49). Portanto, a origem da família, nessa época, está ligada ao conjunto de bens (posse e propriedade) que cada grupo familiar possuía.

Com essa formação entre família e bens, surge a formatação do casamento. Para os romanos, o casamento era um estado de fato, que produzia efeitos jurídicos. De forma paralela, existia ainda a figura do concubinatus, que consistia em toda união livre entre homem e mulher na qual não ocorre o affectio maritalis, efeito subjetivo do casamento e significava o desejo de viver com o parceiro para sempre. (GAGLIANO; PAMPLONA, 2020, p. 49). Desta forma, fica evidente que, no Império Romano, existiam o casamento, com formalidades e o chamado concubinatus, expressão que deu origem ao "concubinato" e à união estável.

Ainda em Roma o casamento era destinado aos homens livres, consistindo em um ato privado, mas que produzia efeitos jurídicos (GAGLIANO; PAMPLONA, 2020, p. 110). Observa-se que a cerimônia do casamento ocorria do ambiente familiar e, para estabelecer efeitos jurídicos, era necessária a presença de testemunhas, úteis em caso de contestação (VEYNE, 2009, p. 45). Portanto, a contestação era uma forma de "denunciar" a impossibilidade de realizar-se o casamento, pois só podiam casar-se os homens que não eram escravos; portanto, livres e o ato solene realizado entre membros da família.

Com o surgimento do Cristianismo, há a condenação das uniões livres e o casamento é instituído como sacramento, pondo em relevo a comunhão espiritual dos nubentes, cercando-a de solenidade perante a autoridade religiosa (VENOSA, 2003, p. 19). A partir do 
Cristianismo é que o casamento torna um ato solene, formal e constituidor único de família, não se concebendo outro que não o casamento. As uniões que não eram sacramentadas eram designadas como uniões livres e, por conseguinte, formada de párias, ou seja, pessoas excluídas da sociedade, pois viviam em desacordo com os ditames da "Santa Madre Igreja".

Assim que o casamento passou a sacramento de forma hegemônica na sociedade ocidental, as demais composições ou arranjos familiares passaram a ser marginalizados (GAGLIANO; PAMPLONA, 2020, p. 50). Vê-se que enquanto na sociedade romana a composição da família era multifacetária, o casamento, para o cristianismo, passa a constituir a única condição para se estabelecer efetivamente a família.

Com isso, a sociedade passa a se organizar em função da família e o intervencionismo estatal institui o casamento como regra de conduta. Uma convenção social para organizar os vínculos interpessoais. Essa foi a forma encontrada para impor limites ao homem. Em uma sociedade conservadora, para merecer aceitação social e reconhecimento jurídico, o núcleo familiar dispunha de perfil hierarquizado e patriarcal. Necessitava ser chancelado pelo que se convencionou chamar de matrimônio, pela forte influência da igreja (DIAS, 2020, p. 43).

Durante o período do Brasil-Colônia, vigorou o sistema patriarcal, formada de pai, mãe e filhos, oriundos do casamento religioso. As Constituições do Império (1824) e a Constituição da República (1891) mantiveram o casamento como forma de formação da família. O primeiro Código Civil (1916) adota o casamento civil e/ou religioso como forma de se constituir a família.

Apesar da rejeição social e de repúdio do legislador, vínculos afetivos fora do casamento sempre existiram. Tanto que o Código Civil Brasileiro de 1916 omitiu-se em regrar tais relações extramatrimoniais, indo além, tentando puni-las. As relações oriundas sem o selo do casamento eram rotuladas como concubinato (DIAS, 2020, p. 574). A autora afirma fatos sociais ocorridos no Brasil no século XIX e início do século XX, quando se publicou o Código Civil, em que as relações de uniões livres já existiam entre nós, mas que foram logradas pela lei.

Com o passar do tempo, as uniões extramatrimoniais acabaram por merecer a aceitação da sociedade, levando a atual Constituição Federal a dar uma nova dimensão à concepção de família (DIAS, 2020, p. 574). A família toma, assim, nova forma, novo modelo e as novas modalidades de família passam a ser respeitadas pela sociedade. Foi, então, que as uniões estáveis passaram a ser descritas na Lei.

Atualmente, julgados dos Tribunais Superiores, dentre eles o Supremo Tribunal Federal, entendem que o concubinato é definido como uma relação extraconjugal sem 
possibilidade de casamento e a união estável é considerada a união entre pessoas, como entidade familiar. Apesar de todo o panorama adverso, o Supremo Tribunal Federal edita a Súmula 380, em 03 de abril de 1964, nos seguintes termos: "Comprovada a existência da sociedade de fato entre os concubinos, é cabível a sua dissolução judicial, com a partilha do patrimônio adquirido pelo esforço comum".

Apenas com o advento da chamada Nova República é que a Constituição Federal (1988) estabelece a união estável. Mas discussões na sociedade contrárias ao que dispõe a Constituição Federal fizeram perdurar o preconceito da sociedade brasileira em relação à união estável, vez que a sociedade não aceitava este tipo de relação e defendia a tese que tal união não seria a forma legal de se constituir família.

Após a publicação da Constituição Federal de 1988 surgem duas leis que tratam da União Estável: A Lei 8.971/1994, que trata dos alimentos e sucessão dos conviventes e a Lei 9.278/96, com maior abrangência, não quantifica prazo de convivência e estabelece direitos semelhantes ao casamento, como o direito real de habitação e a competência da Vara de Família. Em termos jurídico-legais, assim se inicia a legalização da união estável no Brasil.

Assim, a união estável surge como um instituto independente e diferente do casamento, embora não se afastem alguns pontos de contato entre ambos. A união estável se distingue fundamentalmente do casamento, naquilo que diz respeito à convivência, mas equipara ao $c a-$ samento nos direitos de cada um. O traço que os distingue está na espontaneidade da formação da convivência familiar, em tudo oposta ao matrimônio. A união estável oferece conteúdo flexível, não com um dever de fidelidade, típico dever do casamento, mas com o dever de lealdade (SHREIDER, 2020, p. 1.306).

Para Vilaça (2019), “a união estável, de hoje, nada mais é na sua aparência, do que o antigo casamento de fato ou presumido, pois os conviventes sentem-se casados, embora sem as formalidades do casamento civil” (VILAÇA, 2019, p. 215).

\section{Semântica do Acontecimento: pressupostos teóricos}

A análise semântica que empreendemos é desenvolvida levando em conta a constituição dos sentidos na enunciação. Interessa-nos as relações que os termos tomam nessas enunciações. Por isso, a enunciação se constitui pela relação do funcionamento da linguagem e a sua exterioridade e traz para o interior das reflexões de linguagem a questão da subjetividade, da história, do social e do político.

Podemos, então, observar em Guimarães (2002), que a linguagem fala de algo e o objetivo da Semântica do Acontecimento é tomar como lugar de observação a construção 
do sentido do enunciado. Para o autor, o enunciado ocorre no momento da enunciação, isto é, no momento em que há a relação do sujeito com a língua. De acordo com o mesmo linguista, a enunciação é tomada "enquanto acontecimento de linguagem e se faz no acontecimento da língua” (GUIMARÃES, 2002, p. 8). Os sentidos não são formados porque são referência de algo, são decorrência de uma ação enunciativa (GUIMARÃES, 2002, p. 9).

A enunciação não ocorre no tempo cronológico, porque possui sua própria temporalidade e esta funciona a partir do acontecimento do dizer. Para GUIMARÃES, (2002), a enunciação é,

[...] um acontecimento de linguagem perpassado pelo interdiscurso, que se dá como espaço de memória do acontecimento. É um acontecimento que se dá porque a língua funciona ao ser afetada pelo interdiscurso. É, portanto, quando o indivíduo se vê interpelado como sujeito e se vê como identidade que a língua se põe em funcionamento. (GUIMARÃES, 2002, p. 70)

A linguagem acontece no espaço da enunciação, que é o espaço de relações de línguas no qual elas funcionam na sua relação com falantes. A língua é dividida e faz produzir sentido e este funcionamento se dá porque as línguas tomam os falantes. Para GUIMARÃES (2010), além da língua e do sujeito, elementos importantes para esse conceito, o autor traz o real, que para ele é, "a que o dizer se expõe ao falar dele", e a temporalidade. Nessa proposta, permite-se compreender que não é o sujeito que temporaliza, é o acontecimento que instala sua própria temporalidade.

Assim, para o semanticista (2002),

[...] é um acontecimento que temporaliza: uma temporalidade em que o passado não é um antes, mas um memorável recortado pelo próprio acontecimento que tem também o futuro como uma latência de futuro. O sujeito não fala no presente, no tempo, embora o locutor o represente assim, pois só é sujeito enquanto afetado pelo interdiscurso, memória de sentidos, estruturada pelo esquecimento, que faz a língua funcionar. Falar é estar nessa memória, portanto, não é estar no tempo (dimensão empírica). (GUIMARÃES, 2002, p. 14)

Assim, é por isso, que o que é dito no presente só significa porque o acontecimento rememora um passado e projeta uma futuridade, isto é, abrem-se novas interpretações. Para Guimarães (2018, p. 38) o acontecimento é sempre uma nova temporalização, um novo espaço de conviviabilidade de tempos, sem o qual não há sentido, não há acontecimento de linguagem, não há uma enunciação.

O acontecimento se dá a partir da relação do sujeito com a língua, enquanto uma prática política no sentido de que, para Guimarães (2002, p. 16), o político “é caracterizado pela contradição de uma normatividade que estabelece (desigualmente) uma divisão do real e a afirmação de pertencimento dos que não estão incluídos". Para ele, o político é um 
conflito a partir da divisão normativa e desigual do real, onde os desiguais afirmam seu pertencimento e nos permite dizer que o político afeta e divide materialmente a linguagem por uma contradição que instala um conflito de sentidos no centro de dizer.

Outra questão importante ao estudarmos o acontecimento de linguagem como político é entendermos como se estabelecem os espaços de enunciação. Para Guimarães (2002), tais espaços são

[...] espaços de funcionamento de línguas, que se dividem, redividem, se misturam, desfazem, transformam por uma disputa incessante. São espaços "habitados" por falantes, ou seja, por sujeitos divididos por seus direitos ao dizer e aos modos de dizer. São espaços constituídos pela equivocidade própria do acontecimento. (GUIMARÃES, 2002, p. 18)

Para Guimarães, é esse espaço de enunciação que torna a língua uma prática política e falar é assumir a palavra nesse espaço dividido entre línguas e falantes. Para Guimarães (2002), “enunciar é estar na língua em funcionamento. E a língua não funciona no tempo, mas pelas relações semiológicas que tem". Para o mesmo autor, o uso da palavra ocorre em cenas enunciativas, que são caracterizadas pelos modos específicos de acesso a ela (palavra), dadas as relações entre as figuras de enunciação e as formas linguísticas. Desta forma, podemos caracterizar a cena enunciativa como,

\footnotetext{
[...] um espaço particularizado por uma deontologia específica de distribuição dos lugares de enunciação do acontecimento. Os lugares enunciativos são configurações específicas do agenciamento enunciativo para "aquele que fala" e "aquele para quem se fala". Na cena enunciativa "aquele que fala" ou "aquele para quem se fala" não são pessoas, mas uma configuração do agenciamento enunciativo. São lugares constituídos pelos dizeres e não pessoas donas do dizer. (GUIMARÃES, 2002, p. 22)
}

Assim, as cenas enunciativas se constituem como um espaço de distribuição de lugares no espaço da enunciação, tais como: "aquele que fala" (alocutor) e "para quem se fala" (alocutário), isto porque os falantes não são donos do seu dizer. Ademais, o direito ao dizer é político e desigualmente dividido. Segundo Guimarães (2002, p. 23) "a divisão de lugares se faz pela temporalização própria do acontecimento. Neste sentido a temporalidade específica do acontecimento é fundamento da cena enunciativa.".

Levando em consideração tais fundamentos, assumir a palavra "é por-se no lugar de quem enuncia, o lugar do Locutor que vou chamar de Locutor (com maiúscula) ou simplesmente L. L é então o lugar que se representa no próprio dizer, como fonte desse dizer" (GUIMARÃES, 2002, p. 23).

O Locutor não fala por si, mas está compreendido em um lugar, ele se representa como origem do que se enuncia, pois é preciso que ele não seja ele próprio, mas um lugar 
social de locutor. Assim, há divisão no acontecimento, isto porque falar, enunciar, pelo funcionamento da língua no acontecimento, é falar enquanto sujeito. E é aí, que fala de um lugar social, representado pelo locutor $\mathrm{x}$.

Ademais, o autor ainda caracteriza ao que ele chama de "lugares de dizer". Lugares estes ocupados pelo que ele chamou de enunciadores, como,

\begin{abstract}
o enunciador individual, quando a enunciação representa o Locutor como independente da história; enunciador-genérico, quando a enunciação representa o Locutor como difuso num todos em que o indivíduo fala como e com outros indivíduos; enunciador-universal, quando a enunciação representa o Locutor como fora da história e submetido ao regime do verdadeiro e do falso. GUIMARÃES, 2002, p. 26)
\end{abstract}

\title{
Os procedimentos de análise: reescrituração, articulação e Domínio Semântico de
}

\section{Determinação (DSD)}

Para análise e interpretação dos enunciados, enquanto enunciados de um texto a serem trazidos ao presente trabalho e buscando sempre interpretar a construção dos sentidos produzidos nesses textos (enunciados), trazemos dois recortes, nos quais vamos refletir acerca do próprio texto e das relações de sentido que ali existem. Iremos fazer a nossa reflexão sobre textos jurídicos, conhecidos nesse meio como "textos doutrinários", pois proveniente de dois juristas. Os juristas são intérpretes da Lei, mas podem e fazem opiniões acerca do texto da lei.

Quando nos propomos a fazer uma análise de textos à luz da Semântica do Acontecimento, buscamos, conforme diz Eduardo Guimarães, os procedimentos de análise, especialmente, a reescrituração, a articulação, paráfrases e, por último, apresentaremos o DSD, isto é, o Domínio Semântico de Determinação que é a análise da palavra.

Assim, Guimarães (2002, p. 28) a reescrituração é uma operação que significa, na temporalidade do acontecimento, o seu presente. Ainda em Guimarães (2018, p. 85) "A reescrituração é o modo de relação pelo qual a enunciação rediz o que já foi dito". "Há reescrituração quando um elemento Y de um texto (uma palavra, uma expressão, por exemplo) retoma um outro elemento X do texto. Neste caso Y reescritura X".

A reescrituração pode apresentar-se de diversas maneiras. Segundo Guimarães, a reescritura pode ser por:
a) Expansão - quando amplia o que está dito;
b) Definição - quando estabelece uma relação de definição com o que está dito;
c) Elipse - quando há uma omissão de um termo;
d) Condensação - quando totaliza um termo do enunciado; 
e) Substituição - quando há troca de um termo por outro;

f) Repetição - quando há reafirmação de um termo por outro.

Podemos verificar ainda, as constituições de sentidos a partir da reescrituração, tais como:

a) Sinonímia - quando uma palavra ou expressão tem o mesmo sentido que outra;

b) Especificação - quando um termo oferece sentidos a outro semelhante;

c) Enumeração - quando há diversas caracterizações de um termo;

d) Desenvolvimento - produz um desenvolvimento de sentidos;

e) Generalização - quando determina aqui que foi generalizado;

f) Totalização - determina as partes do texto, há uma totalização de tudo.

Já a articulação para Guimarães (2018, p. 80), “Chamo de articulação relações como predicação, complementação (relação determinante - determinado), e outras, tradicionalmente consideradas no estudo da frase ou enunciado.", ou ainda, "uma articulação é uma relação de contiguidade significada pela enunciação". Ratifica tal entendimento, quando afirma que a articulação [...] diz respeito às relações próprias das contiguidades locais. De como o funcionamento de certas formas afetam outras que elas não redizem Guimarães (2007, p. 87).

O DSD (Domínio Semântico de Determinação) é a análise de uma palavra. Ele representa uma interpretação do próprio processo de análise e deve ser capaz de explicar o funcionamento do sentido na palavra no corpus especificado. Ele mostra como o funcionamento das palavras na enunciação constituem sentido (designação, referência, entre outras coisas). O DSD é a caracterização de como, no acontecimento da enunciação, uma língua se movimenta ao funcionar" (GUIMARÃES, 2007, p. 96). Podemos afirmar que o DSD é a representação das relações de determinação do termo analisado. Para tanto, usase, na construção do DSD símbolos específicos $(\perp, \vdash,-, T)$ para as relações de determinação, como (---------------) para as relações de sinonímia e (__ ções de antonímia.

Para realizarmos os procedimentos acima apontados, utilizaremos o recorte. Do ponto de vista da análise enunciativa, o recorte é um fragmento do acontecimento da enunciação. Não se trata simplesmente de uma sequência, mas de formas linguísticas que aparecem como correlacionadas em virtude de terem uma mesma relação com o acontecimento, independentemente da posição na sequência (GUIMARÃES, 2008). Podemos, assim, estabelecer o seguinte procedimento: 1) toma-se um recorte qualquer, a partir de uma leitura atenta e mesma repetida do texto, e produz-se, considerando uma posição teórica, uma 
descrição de seu funcionamento; 2) interpreta-se seu sentido na relação com o texto em que está integrado; 3) chega-se a, ou toma-se, outro recorte e faz-se dele uma descrição; 4) interpreta-se seu sentido na relação com o texto em que está integrado, tendo em vista a interpretação feita do primeiro recorte; 5) busca-se um novo recorte etc, até que a compreensão produzida pelas análises se mostre suficiente para o objetivo específico da análise. Aqui é preciso reiterar que tanto os recortes como a interpretação de seu funcionamento se fazem a partir da posição teórica específica. É essa posição que nos indica a pertinência do que recortar. A isso se junta a leitura atenta e reiterada do texto a ser analisado (GUIMARÃES, 2017, 58-60).

Ademais, utilizaremos ainda, como procedimento de análise, o parafraseamento ou paráfrase. Podemos afirmar que "O parafraseamento ou paráfrase é um mecanismo interpretativo que o analista lança mão para tecer a análise, projeta determinada interpretações sustentáveis a partir da relação de sentido de cada acontecimento" (VENTURA; SOUZA, 2019, p. 6), ou seja, o analista utiliza a paráfrase como um auxílio na análise do texto, como uma forma de buscar os sentidos ali existentes, ou seja, nas paráfrases construídas encontramos as possibilidades de construção dos sentidos.

$\mathrm{Na}$ análise, serão observados os procedimentos de reescritura e articulação, as paráfrases e a construção do Domínio Semântico de Determinação (DSD), como mecanismo de descrição da nossa análise.

\section{Resultados e discussões}

Nesta análise, fizemos recortes do livro Novo Curso de Direito Civil - Direito de Familia, Volume 6, da autoria de Pablo Stolze Gagliano e Rodolfo Pamplona Filho, acerca da União Estável, Capítulo XIX.

Assim, separamos dois excertos do livro anteriormente citados. Os excertos estão no Capítulo XIX, “União Estável, sendo ambos os encontrados no item 4, "Conceito de União Estável”, página 417 e o segundo, página 418. Seguem os excertos:

(R1) [...] Diferentemente do casamento, entidade familiar essencialmente formal e geradora de estado civil, a união estável é desprovida de solenidade para sua constituição. (Excerto 1, Direito de Família, p. 417, grifo nosso). 
Pela análise que empreendemos, tem-se que no corpus o termo casamento é construído como "entidade familiar essencialmente formal e geradora de estado civil" e entidade familiar, como “[...] desprovida de solenidade para sua constituição" (grifo nosso). O que não chama a atenção neste recorte, é a oposição entre casamento e união estável.

Em relação às reescrituras, observa-se que o termo "entidade familiar essencialmente formal e geradora de estado civil" reescreve "casamento" por substituição, com sentidos de definição. Há, ainda, uma reescritura por substituição entre "união estável” e “desprovida de solenidade para sua constituição" (grifo nosso), produzindo, também, sentidos de definição.

Os termos "formal" e "geradora" estão articulados por coordenação com "entidade familiar" e a expressão "de estado civil” está articulada por dependência com "geradora", com sentidos de que o "casamento" é realizado com "formalidades" e produz novo "estado civil" (grifos nossos).

A partir dessas relações de linguagem, o recorte nos remete ao memorável de que a noção de família é anterior ao do instituto do casamento, pois a formação dos núcleos familiares na Antiguidade não pressupunha uma ritualização, uma formação social e religiosa.

O casamento, como instituição, por sua vez, deriva efetivamente de um sistema organizado socialmente, com o estabelecimento de regras formais, de fundo espiritual ou laico. Ocorria entre pessoas livres, geralmente, com características religiosas, indissolúvel, como instrumento de reunião de patrimônios, instituído em Roma e, posteriormente, na Idade Média, pois a união permitia a propagação e continuidade do culto nas famílias constituídas pelos nubentes, descaracterizando o casamento de qualquer conotação afetiva.

Nessa perspectiva, percebe-se um memorável em que o casamento ocorria com interesses religiosos, sendo divino e se fazia para e por Deus, em que se reunia patrimônios. Agrega-se a tal memorável a construção de sentidos do casamento na atualidade em que há formalidades e solenidades, com um viés sacralizado, em que surgem sentidos de indissolúvel porque divino e a gera diversos efeitos no grupo familiar como o estado civil dos casados, estabelecendo ritos e efeito.

Por outro lado, a união estável surge anterior ao casamento, ainda, nas organizações tribais e nos remete ao memorável das relações puramente afetivas, entre pessoas que se juntavam por amor. Entretanto, com o advento do casamento, passar a sofrer preconceitos, com absoluta ausência de tutela jurídica e ocorria entre pessoas impedidas de se casarem ou que se juntavam apenas pelos laços do afeto. Observa-se no memorável, que a união estável é livre, não incidindo aspectos religiosos e/ou econômicos e, por isso geralmente acontecia 
por amor, por afeto. Ao longo do tempo, sofre o preconceito da sociedade cristã estabelecida, mas perdura, sendo descrita e protegida no Século XX, no Brasil, a partir da Constituição Federal de 1988.

Nota-se, nesta análise, que existe um conflito enunciativo pela atribuição de sentido às palavras casamento e união estável. $\mathrm{O}$ casamento seria aquele formado com formalidades e gerador de estado civil; enquanto isso, a união estável é desprovida de quaisquer formalidades e solenidades, não gerando novo estado civil.

Assim, podemos ter as seguintes paráfrases:

1) O casamento tem cunbo religioso, social e patrimonial;

$\left.2^{a}\right)$ O casamento tem solenidades exigidas por lei e gera estado civil;

$3^{a}$ ) A união estável não possui nenbuma solenidade nem gera novo estado civil.

Essas paráfrases indicam possibilidades de sentido de família no recorte, pois o "casamento" ao constituir família, deve seguir solenidades e formalidades legais e faz gerar um novo "estado civil”, enquanto a "união estável”, não segue ritos e solenidades. Temos, nesta cena enunciativa, um Enunciador-coletivo, pois não fala de um lugar individual, mas fala no lugar de jurista, quando diz, “[...] casamento, entidade familiar essencialmente formal e geradora de estado civil" e, mais: "Diferentemente [...] a união estável é desprovida de solenidade para sua constituição". Observamos que o advérbio modal "diferentemente" constrói sentidos opostos entre o "casamento" e a “união estável”. "Diferentemente" oferece sentidos de desigual, algo que está em oposição a outro termo e pelos sentidos produzidos “casamento” e “união estável” são diferentes, opostos. Ademais outro advérbio, “essencialmente”, estabelece sentidos de que para o "casamento" ser válido, é necessário seguir as formalidades previstas em lei, porque são fundamentais, sendo, portanto, o casamento um ato solene.

Assim, o alocutor-jurista apresenta “casamento" como sendo apontado como uma “entidade familiar"; portanto, "casamento" forma "família” . E, também, “essencialmente formal”, isto é, para a constituição do “casamento" são exigidas formalidades; por conseguinte são obrigatórias regras, que devem ser cumpridas. Ademais, essa "entidade familiar", que surge do "casamento", é geradora e faz nascer um "estado civil", ou seja, com o "casamento" adquire-se um novo "estado civil".

Observamos que a "união estável” é definida como sendo "desprovida de solenidade”. Com isso, percebemos que a “união estável” não precede de rituais ou atos solenes para sua constituição. A “união estável” é estabelecida sem quaisquer protocolos, 
formalidades. Portanto, a constituição da “união estável” não contém ritos, ela se constitui pela própria união entre pessoas.

Essa interpretação oferece sentidos de que ambos são formadores de família. Enquanto o "casamento" exige solenidades e estabelece consequências como um gerador de estado civil, a “união estável” não possui solenidades, sendo estabelecida pela vontade dos que querem viver em companheirismo. Assim, não gera estado civil, pois a sociedade cristã, patrimonial e conservadora das tradições milenares do casamento, vê a "união estável" como uma união inferior ao "casamento".

Levando em conta, tais interpretações, temos o seguinte DSD para o enunciado (Quadro 1):

Quadro 1: DSD de casamento x união estável

Casamento - entidade familiar essencial formal e geradora de estado civil

União estável $\vdash$ desprovida de solenidade

T

Inferior ao casamento

Fonte: Elaboração própria

No enunciado, o alocutor-jurista afirma que o "casamento" é uma "entidade familiar", possuindo solenidades e que faz gerar um novo "estado civil"; enquanto a "união estável” é a união desprovida de solenidades e, por isso, não gera estado civil.

As observações e análises apontadas nos levam a construção de sentidos opostos entre "casamento" e "união estável”; enquanto o primeiro é considerado uma "entidade familiar", portanto, formador de família, com formalidades e geradora de "estado civil", a segunda, ou seja, a “união estável” não possui solenidades para sua formação, sendo, por conseguinte, inferior ao "casamento". Assim, o enunciado analisado projeta uma futuridade resultante da relação entre os memoráveis no acontecimento. Ademais, possibilitam entendimentos diversos nos formadores de família, casamento e união estável, muito embora tenham surgido em momentos distintos com características diversas, mas formam família.

(R2) [...] Por ser uma simples união de fato não condicionaria ao ditame formal impositivo da diversidade sexual - permitindo o reconhecimento da relação familiar entre companheiros - sejam do mesmo sexo, sejam de sexo diverso (Direito de Família, p. 418). 
Pela análise que empreendemos, tem-se que no corpus o termo união de fato é construído como "[...] não condicionaria ao ditame formal impositivo da diversidade sexual - permitindo o reconhecimento da relação familiar entre companheiros - sejam do mesmo sexo, sejam de sexo diverso" (grifo nosso). O que não chama a atenção neste recorte, é uma reescritura entre união de fato e união estável.

Observamos no enunciado que "relação familiar" se refere à relação entre pessoas ligadas por laços entre si e de afeto no âmbito da família. Como a "relação familiar" é uma relação que ocorre na "família", o termo "relação familiar" que aparece no enunciado substitui o termo "família". Com isso, pela análise efetuada, podemos dizer que o termo "relação familiar" é reescrituração por substituição de "familia", havendo entre os termos "relação familiar" e o termo "família" uma relação de sinonímia.

Ademais, há uma reescritura por substituição de "união de fato" e "união estável". Por outro lado, "união de fato" e união estável determinam "relações familiares e, portanto, "família".

Por outro lado, a expressão "relação familiar" está articulada com "entre companheiros", que por sua vez está articulado com "sejam do mesmo sexo, sejam de sexo diverso", demonstrando sentido de que a "união de fato" ou "união estável" pode acontecer entre pessoas do mesmo sexo ou de sexo diferente.

Ainda, "união de fato" está articulado com "informal", oferecendo sentidos de que não possui formalidades ou solenidades. "União de fato" está articulado com "ditame formal impositivo da diversidade sexual". Verifica-se nesta relação sentido de que a "união de fato" não está condicionada às regras, ou seja, às descrições legais, pois é uma união decorrente do afeto e da vontade entre as pessoas e não da lei.

Por estas relações de linguagem, nos remete ao memorável de que a "união de fato" ou "união estável" ocorre entre as pessoas, sem formalidades e solenidades. É anterior ao casamento e surge nas primeiras comunidades tribunais, passando pelas civilizações gregas e romanas, (até a contemporaneidade), sem nenhuma determinação de que essas "uniões de fato", juridicamente denominada "união estável", fossem constituídas entre pessoas do mesmo sexo ou de sexo diverso. Com efeito, essas relações de "união estável" ou "uniões de fato" podem ser heteroafetivas, ou seja, constituída por pessoas de sexo diverso; ou homoafetivas, realizadas por pessoas do mesmo sexo, conforme indica o enunciado. Quanto às uniões homoafetivas, após o surgimento das civilizações cristãs, sofreram todas as formas de opressão: proibições, escárnio público, torturas, prisões e morte. 
A partir dessas considerações é possível dizer que a cena enunciativa que se constitui no recorte (R-2) traz um conjunto de sentidos que podem ser parafraseados da seguinte forma:

$1^{\text {a) }}$ A união estável não possui formalidades e solenidades, pois se trata de união de fato;

$2^{\mathrm{a}}$ ) A união estável não se enquadraria às imposições legais;

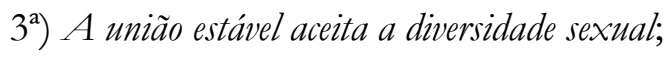

$4^{\mathrm{a}}$ ) A união homoafetiva sofre preconceitos a partir do advento do cristianismo.

O DSD abaixo(Quadro 2) ilustra tais relações:

Quadro 2: DSD de união estável

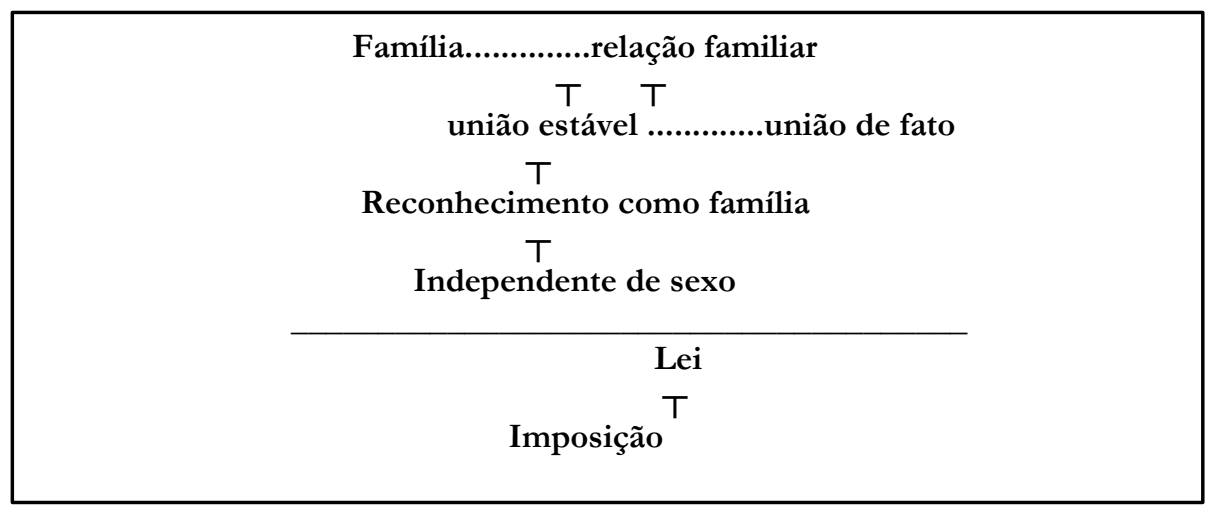

Fonte: Elaboração própria

O DSD aponta sentidos que nos revelam que o termo "relação familiar" tem uma relação de sinonímia com família, vez que as relações familiares, ditas no enunciado, se localizam no seio da família. O termo "união de fato" estabelece uma relação de sinonímia com "união estável”, pois “união de fato" refere-se à "união estável, definida em lei como tal e estabelece sentido de uniões livres entre pessoas (independentemente de sexo), que se relacionam pelo afeto, o que caracteriza a "união estável", portanto.

Assim, temos que o locutor-jurista nos aponta a "união estável" como sendo uma "união de fato", por ser simples e de fato, ou seja, sem solenidades e formalidades, características que surgem dos sentidos e da expressão "união de fato". Afirma que a "união estável" é uma relação familiar, portanto, sendo reconhecida como uma modalidade de "família", não se condicionando aos "ditames formais impositivos da diversidade sexual", ou seja, a "união de fato" não se constitui das imposições da Lei.

Assim sendo, "União estável" e "união de fato" determinam "relação familiar" e, portanto, de "família". Por outro lado, "reconhecimento como família" determina "união de fato" e "união estável". Assim, observamos, na análise, que "união estável” ou "união de 
fato" constituem família, ou seja, são "relações familiares". Por outro lado, as "uniões de fato" não obedecem à imposição legal. Essas "uniões de fato" nasceram da vontade daqueles que desejam constituir uma relação familiar oriunda do amor, sem quaisquer entraves legais. É da vontade dos companheiros de estarem juntos independentemente dos regramentos legais que funciona de fato. Ora, a interpretação da "união de fato" não segue estritamente o que está na Lei, admitindo a possibilidade de que essas relações podem se dar entre companheiros do mesmo sexo ou de sexos diferentes; portanto, ela se constitui, independentemente de sexo.

\section{Conclusão}

As relações de sentido e as paráfrases estabelecidas nesta análise nos possibilitam pensar sobre os sentidos de família a partir de abordagens acerca de união estável que vêm sendo produzidas no espaço político-jurídico brasileiro, isto porque as cenas enunciativas do corpus analisado, desde o início da formação da família, na história humana, até os enunciados analisados que permeiam este trabalho, apontam para lugares em que se percebe um embate de sentidos, que coloca de um lado a lei, a qual impõe um casamento formal, com caráter heterossexual, enquanto a união estável, também denominada no recorte, como união de fato, é constituída "à margem" da lei, sendo desprovida de solenidades e inferior ao casamento.

Observamos, então, que por conta do agenciamento do locutor-jurista, a palavra $f a$ mília pode ter alguns sentidos e outros ficarem silenciados.

Percebemos na obra analisada que a família constituída pelo casamento é mais respeitada e aceita socialmente; enquanto que aquela constituída pela união estável é vista com preconceito e tem menos aceitação. Ademais, observamos que o casamento é realizado com formalidades e solenidades; todavia a união estável é estabelecida através da vontade e do afeto entre aqueles que se unem.

Família significa, então, um grupo de pessoas, unidas pelo casamento, bem como pela união estável. A formação da família pelo casamento é mais valorizada pelo grupo social. Em relação à família oriunda da união estável nos remeteu a memoráveis de não-aceitação, o que reflete ainda hoje.

A formação de família pelo casamento tem cunho religioso, social e patrimonial, mas a união estável, outra modalidade de construção de família, não advém da religiosidade, nem mesmo estabelece estado civil nem possui solenidades e formalidades. 
$\mathrm{Na}$ união estável, há diversidades de parceiros, podendo ser constituída por pessoas de gêneros diversos ou do mesmo gênero. Assim, embora a existência de imposições legais para a formação do casamento, a união estável é uma simples união de fato, portanto, inferior ao casamento.

As diferentes designações da palavra familia estão relacionadas às diferentes formas de se descrever as relações sociais brasileiras. Esta palavra significa diferentemente na obra apontada, embora na escrita pareça ter um único sentido, existem sentidos diversos, pois formada a família por diversidades, mesmo com as imposições legais apontadas.

\title{
THE MEANINGS OF THE WORD FAMILY FROM APPROACHES ABOUT A STABLE UNION
}

\begin{abstract}
This paper has as objective analyze the meaning of the word family in enunciations resident on the book Direito de Família", of authorship of Pablo Stolze Gagliano and Rodolfo Pamplona Filho, understood a indoctrinated book that aims make the scholars of law read the law and understand it's operation in society. We selected, as a corpus of analysis, three enunciations that indicates how the law sees the organization of the stable union and the possible interpretation of the lawyers. Our analysis will be on the theoretical field of the Semantics of Happening, observing how it is the relation in space of enunciation, which is a political space, built by the announcers and by the language, taking in consideration a memorable that is cut by the selfrelation of the language with the language. The Semantics of Happening conceptualizes the enunciation as a political practice, that installs the conflict in the center of saying, and to who the constitution of meanings is historical and the relation of the subject with the language occurs in happening. As a methodological support, will be observed the meanings and the relations of the terms in texts extracted from the book "Direito de Família", starting from the relations in enunciations. Therefore, we utilize the proceedings of rewriting, articulations and the Semantic Domain of Determination (S.D.D). In addition, we utilize paraphrases that will serve of support to possible conclusions. Can be seen that the analyzed enunciations can exhibit different meanings of family in political and legal sphere.
\end{abstract}

KEYWORDS: Law; Meanings; Semantic; Stable Union.

\section{REFERÊNCIAS}

AZEVEDO, Álvaro Villaça. Curso de direito civil: direito de família. 2. ed. São Paulo: Saraiva Educação, 2019.

GAGLIANO, Pablo Stolze; PAMPLONA, Rodolfo. Curso de direito civil. Vol. 6. Direito de Família. São Paulo: Saraiva, 2020.

GUIMARÃES, Eduardo. Semântica do acontecimento. Campinas: Pontes, 2002. Os limites do sentido. Campinas: Pontes, 2002.

Domínio Semântico de determinação. In: GUIMARÃES, Eduardo; MOLICCA, Maria Cecília. A palavra. Forma e Sentido. Campinas: Pontes, 2007. p. 77-96. . Análise de texto: procedimentos, análises, ensino. 2. ed. São Paulo: Hucitec, 2017 . Semântica: enunciação e sentido. Campinas, Pontes, 2018.

LOBO, Paulo. Direito Civil: Famílias. 2. ed. São Paulo: Saraiva, 2009.

SCHREIBER, Anderson. Manuel de direito civil contemporâneo. 3. ed. São Paulo: Saraiva, 2020. 
SOUZA, Danilo Sobral de; VENTURA, Adilson. Sentidos de impeachment em denúncias contra Dilma Rousseff: Uma Análise a partir da Semântica do Acontecimento. Revista de Psicologia, v. 13, n. 43, p. 175-186, 2019.

VENOSA, Silvio de Salvo, Direito civil: direito de família. 3. ed. São Paulo: Atlas, 2003.

VEYNE, Paul. História da vida privada - do Império Romano ao ano mil. São Paulo: Companhia das Letras, 2009.

\section{Agradecimentos}

Os autores agradecem a Universidade Estadual do Sudoeste da Bahia (Uesb) e ao Programa de Pós-graduação em Linguística (PPGLin) pelo suporte educacional e espacial.

Recebido em: 29/05/2021.

Aprovado em: 11/06/2021. 